\title{
Maximização da lucratividade em produção conjunta: um caso na indústria frigorífica
}

\author{
Ricardo Augusto Cassel \\ José Antônio Valle Antunes Jr. \\ UNISINOS \\ Vilmar Oenning \\ Unochapecó
}

\begin{abstract}
Resumo eficaz do prisma da tomada de decisão.

Palavras-chave

Frigorífico de aves, custos conjuntos, Pesquisa Operacional.
\end{abstract}

O presente artigo parte do problema do cálculo de custos em indústrias de produção conjunta. Observa-se que a abordagem tradicional adotada para tratar o tema, o método do custo conjunto, apresenta limitações no que tange ao modelo adotado e aos resultados obtidos em termos da análise da lucratividade dos diferentes produtos finais. Como forma de tratar o problema apresenta-se uma abordagem alternativa baseada na Teoria das Restrições suportada por técnicas de Pesquisa Operacional. Visando mostrar as diferenças dos resultados na utilização dos dois métodos, é realizado um estudo de caso em uma unidade de abate e industrialização de aves. Os resultados obtidos, em termos da lucratividade global da operação, apresentam diferenças significativas. A abordagem da Teoria das Restrições aplicada com base na utilização de técnicas de Pesquisa Operacional demonstra-se mais

\section{Maximizing the profitability in joint-production: a case in the poultry industry}

\begin{abstract}
This paper discusses the problem related to the costing in joint product industries. Traditional approaches to this subject present limitations regarding the analysis of the individual profitability of each final product. This problem is discussed and an alternative approach based on the Theory of Constraints, and supported by the Operational Research, is proposed. To demonstrate the differences between this new approach and the traditional one, a case study in a poultry company is presented, and the results are discussed.
\end{abstract}

Key words

Poultry industry, joint costs, Operational Research. 


\section{INTRODUC̣ÃO}

O acirramento da concorrência nos mercados nacional e internacional é cada vez maior. A globalização e a abertura de novos mercados exigem das empresas um incremento na sua competitividade, obtida através da melhoria da qualidade e da satisfação contínua de seus clientes. Com o propósito de competir em mercado onde a concorrência é acirrada, as empresas necessitam adotar métodos de gestão cada vez mais eficazes. Desta forma, torna-se necessário gerar modelos de gestão que sejam capazes de realizar um alinhamento entre as proposições estratégicas, táticas e operacionais, o que requer uma atenção permanente no sentido de construir uma lógica de planejamento, controle e verificação dos resultados econômicos e financeiros obtidos nas diferentes operações realizadas.

No caso do Brasil, até o final de década de 1980 a política industrial adotada era de cunho protecionista. Neste tipo de ambiente, as empresas que atuavam no País tendiam a admitir a ocorrência de desperdícios em seus sistemas produtivos, na medida em que tinham a possibilidade de repassá-los aos clientes.

A partir do início da década de 1990, com a abertura do mercado nacional, foram modificadas as normas de concorrência no mercado, o que tendeu a facilitar a entrada de novos concorrentes. Isto fez com que as empresas que já atuavam no Brasil passassem a adotar medidas visando melhorar a sua capacidade competitiva.

Dentro do contexto descrito sucintamente acima, as empresas brasileiras têm buscado utilizar novas técnicas de gestão da produção e novos princípios e técnicas, que contribuam para melhorar a tomada de decisão, na área de contabilidade de gestão.

Os modelos de gestão propostos devem ser gerados de tal forma que permitam perceber quais são os custos que agregam e que não agregam valor aos clientes. A noção básica consiste em tomar decisões que sejam capazes de otimizar os resultados econômicos e financeiros, tendo em vista a melhor e mais eficaz utilização de sua capacidade instalada. Uma das estratégias possíveis de ser adotadas consiste em gerar controles de produção voltados para um melhor aproveitamento da capacidade instalada. A contabilidade, especialmente a gerencial, necessita preparar-se no sentido de contribuir de forma objetiva neste sentido.

O presente artigo tem por objetivo tratar o tema da contabilidade de gestão de sistemas de produção conjunta em indústrias frigoríficas. A abordagem tradicional propugna a adoção do chamado método dos custos conjuntos. Neste trabalho propõe-se a adoção de um método alternativo baseado nos conceitos propostos no âmbito da Teoria das Restrições, com o apoio de ferramentas oriundas da Pesquisa Operacio- nal. Na seqüência, apresenta-se a problemática da produção conjunta em empresas frigoríficas.

\section{A PRODUC̄̃̃O CONJUNTA EM UMA EMPRESA FRIGORÍFICA DE FRANGOS}

Os sistemas produtivos possuem características que os tornam diferentes. Conhecê-los em profundidade é uma necessidade para os profissionais que tratam da problemática da montagem de sistemas de custeio. Tais características influenciam diretamente na abordagem de custeio e nos procedimentos a serem adotados para melhorar a eficácia das tomadas de decisão.

A produção conjunta constitui-se em um sistema produtivo diferenciado, o que implica em impingir dificuldades no que tange ao custeamento de produtos. A produção conjunta pode ser conceituada como "um fluxo comum de produção até certo ponto, denominado ponto de cisão, e do qual resulta uma multiplicidade de produtos" (VICECONTI; NEVES, 2000). Sendo assim, os produtos conjuntos são sempre relacionados entre si, conseqüentemente o aumento na produção de um determinado produto irá incrementar a produção de outros que surgem no mesmo processo, embora não necessariamente na mesma proporção.

A produção conjunta, uma característica das indústrias de abate de frangos, determina a existência de um relacionamento de todos os produtos finais relativamente fixo e inevitável até o ponto de separação. É no ponto de separação que ocorre a divisão total da matéria-prima inicial em diversos produtos. Após o ponto inicial de separação, os produtos vão tendo agregação de valor através dos diferentes processos produtivos, de forma independente. Porém, a determinação correta dos custos unitários de produção é uma tarefa difícil ou mesmo impossível, independentemente do princípio de custeio utilizado.

Definindo os custos conjuntos, Horngren (1986) postula que:

"[...] custo de um produto conjunto são os custos de um único processo ou série de processos que simultaneamente produza dois ou mais produtos com receitas de vendas relativamente significativas. São os custos totais incorridos até o ponto de separação dos diferentes produtos". (HORNGREN, 1986)

Para Marshall e Dombrowski (2003), os custos conjuntos são os custos de matéria-prima e de processo incorridos até o ponto de separação a partir do qual os diferentes produtos podem ser identificados de forma separada. Estes custos anteriores ao ponto de separação, incluindo matéria-prima, mão-de-obra, depreciação, entre outros, estão relacionados com o conjunto de produtos, não possuindo um relacionamento direto e específico com nenhum deles. Assim, a 
apropriação dos custos aos diferentes produtos finais tende a ser feita de forma arbitrária através da utilização de bases de rateio.

Com o intuito de valorizar os estoques, surgiram sistemas e/ou métodos de custeio visando alocar os custos conjuntos aos diferentes produtos finais. Entre os sistemas e/ou métodos de custeio utilizados pode-se citar a adoção de diferentes bases de rateio, a saber: i) rateio com base no método do valor de mercado; ii) rateio com base nas unidades físicas de produção; iii) rateio com base no método das médias ponderadas. Porém, na medida em que as bases lógicas utilizadas para realizar estes rateios são bastante subjetivas, os resultados obtidos, tanto em termos de custos como de lucratividade individual dos produtos, são passíveis de questionamento.

As indústrias frigoríficas ou abatedouros de aves constituem-se em exemplos de atividades de produção conjunta. Neste caso, todos os produtos principais ofertados no mercado são oriundos de uma única matéria-prima, o frango vivo.

A Figura 1 mostra o processo básico de produção em uma empresa frigorífica de frangos.

Observa-se na Figura 1 que o Processo 01 - Abate - gera um novo grupo de produtos conjuntos. No Processo 02, ao decidir pelo corte da carcaça do frango, obter-se-ão de forma compulsória as pernas com osso, o peito com osso, a asa inteira e o dorso de frango. Os gestores podem decidir por agregar novos processos aos produtos gerados. Porém, não podem optar pela não produção do dorso de frango ou pelo aumento do volume de peito produzido, por exemplo.

Em função das características de produção conjunta deste tipo de sistema produtivo, torna-se muito difícil determinar a lucratividade dos diferentes produtos (por exemplo, a lucratividade de um quilograma de peito de frango desossado).

$\mathrm{Na}$ atividade frigorífica de aves agrega-se mais um fator restritivo significativo relacionado com o tipo de negócio em si, que é a dificuldade significativa de reduzir ou ampliar a "matéria-prima" necessária para abastecer o sistema produtivo - o abate de frangos - em curto prazo. Isto ocorre na medida em que os pintinhos que irão dar origem à "matériaprima" para a produção já foram alojados, em média, 45 dias antes do abate. Especificamente para a redução da produção, deve-se considerar que cada dia a mais que as aves ficam no campo (vivas), elas devem ser alimentadas, reduzindo de forma significativa os resultados econômico-financeiros globais da empresa.

Segundo Goldbarg e Luna (2000, p.16), “o objetivo principal na tomada de decisão empresarial é a maximização da utilidade do decisor, na prática, traduzida pela maximização do lucro ou pela minimização do custo". Na avicultura, para melhorar o processo de decisão, é necessário transpor as dificuldades impostas pelas particularidades e especificidades

Figura 1: Processo de Produção da Indústria de Frangos.

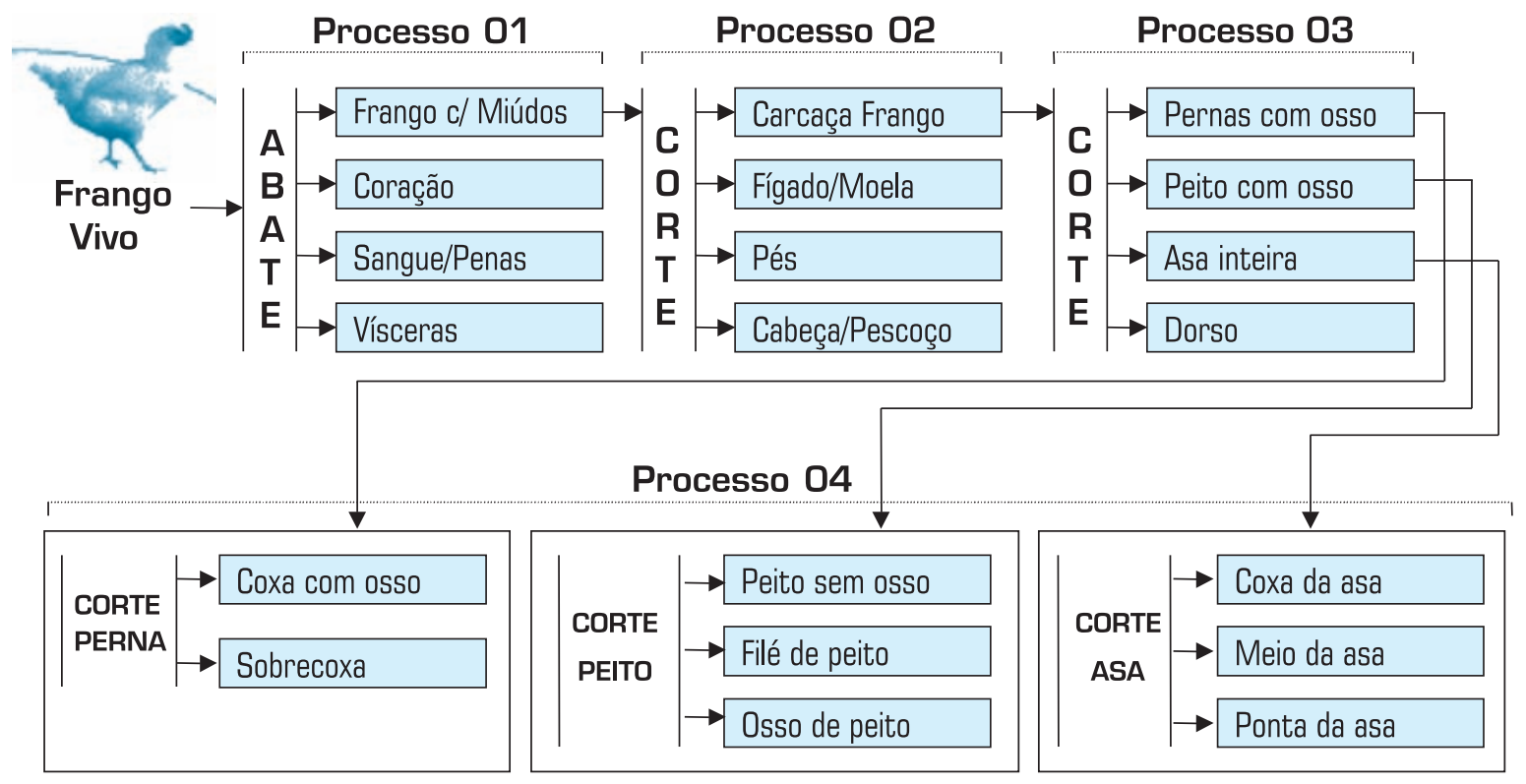

Fonte: Autores 
dos produtos conjuntos em relação à dificuldade de calcular com a precisão necessária os custos de produção.

Um dos caminhos possíveis visando enfrentar as dificuldades de tomada de decisão quando em sistemas de produção conjunta consiste em buscar "a otimização dos resultados globais da empresa..." através da "otimização dos resultados de cada decisão, que ocorre sobre os eventos econômicos" (PEREIRA, 1999). Para que isso ocorra, é necessário que as tomadas de decisões na empresa sejam feitas a partir de uma perspectiva sistêmica e não voltadas apenas para uma lógica local de determinado processo específico.

Dessa forma, é possível pensar que uma análise sistêmica do problema, através de uma análise criteriosa dos recursos escassos e limitantes de produção da empresa, visando a maximização dos mesmos, possa ser um encaminhamento para maximizar a lucratividade das indústrias que trabalham com produção conjunta, entre as quais se incluem as empresas frigoríficas de frangos.

Tendo em vista o tipo de problema explicitado acima associado a empresas frigoríficas de frangos, torna-se necessário que os gestores sejam municiados de ferramentas de gestão apropriadas para qualificar os seus processos de tomada de decisão. Uma abordagem possível consiste em desenvolver ferramentas de gestão que levem em consideração, de forma sistêmica, as diferentes restrições do sistema produtivo - envolvendo as áreas de produção, mercado, tecnologia intrínseca, matérias-primas etc.... - comparandoa com as abordagens classicamente adotadas para alocação de custos e análise da lucratividade individual dos produtos e da lucratividade total da Empresa proveniente da Teoria dos Custos Conjuntos. Uma possibilidade concreta consiste em adotar os princípios da Teoria das Restrições associados a técnicas de Pesquisa Operacional e Programação Linear.

Na próxima seção é apresentado o Referencial Teórico adotado para a realização deste trabalho.

\section{REFERENCIAL TEÓRICO}

O Referencial Teórico adotado para o desenvolvimento do trabalho envolve três tópicos, a saber: i) Os métodos tradicionais de Custo para Produção Conjunta; ii) Os conceitos básicos da Teoria das Restrições; iii) Os conceitos básicos de Pesquisa Operacional e Programação Linear

\section{Os métodos tradicionais de Custo para Produção Conjunta}

Em função do tipo de sistema produtivo, qualquer tentativa de alocar custos conjuntos aos produtos apresenta subjetividade. Porém, devido à necessidade de valoração dos produtos para fins de relatórios e cálculo de impostos, existe a necessidade de alocação de custos conjuntos. Segundo, Hansen e Mowen (2001):
"A principal razão de alocação dos custos conjuntos, é que relatórios financeiros e as leis do imposto de renda federal exigem. O resultado básico do processo de alocação de custos conjuntos é a determinação dos custos de produtos para uso na determinação do resultado e na avaliação dos estoques". (HANSEN; MOWEN, 2001)

Dentre os vários métodos de alocação dos custos conjuntos, destacam-se:

Método de unidades físicas: Neste método os custos conjuntos são distribuídos para os produtos com base em alguma medida física, como quilogramas, toneladas, litros. Este método aloca o total dos custos conjuntos na mesma proporção de unidades físicas produzidas. Por exemplo, se um processo conjunto rende 300 quilogramas de produto $\mathrm{A}$ e 700 quilogramas de produto $\mathrm{B}$, o produto A receberá $30 \%$ e o produto $\mathrm{B}$ receberá $70 \%$ do custo conjunto. Pode ocorrer que o produto final A, embora menos pesado, necessite de um maior esforço de produção para ser fabricado. Neste sentido, deveria absorver um maior valor em termos dos custos do que os rateios realizados puramente por peso. Sendo assim, é possível observar distorções nos resultados obtidos.

Método do valor de venda: em termos de mercado, "este é o método mais utilizado na prática, mais em função da inexistência de outros melhores do que de méritos próprios" (MARTINS, 2003). Este método aloca os custos conjuntos aos produtos com base na participação dos diferentes produtos no mercado, proporcional ao valor de venda de cada produto.

Sendo assim, quanto maior for o valor de mercado, maior será a proporção de custo conjunto alocada ao produto. Martins (2003) destaca que este critério “... seria justo se fosse verdadeira a idéia de que o item de mais alto valor é o que custa mais”. Porém, “...isso não é verdade, já que o preço tende a ser mais uma função de demanda e oferta que de custo de produção" (MARTINS, 2003).

A utilização deste método apresenta limitações em relação ao preço de venda, na medida em que:

“[...] todos os métodos de preços de venda estão sujeitos a uma limitação importante. Onde o custo é determinado pelo preço, o preço não pode ser determinado pelo custo. Portanto, todos os métodos de preço de venda são circulares, para decisões de precificação". (HANSEN; MOWEN, 2001)

Esse método pode ainda ser dividido em: i) método do preço de venda no ponto de separação; e ii) método do preço líquido realizável. No primeiro, os preços de mercado a serem considerados para a distribuição dos custos conjuntos são aqueles que se obteriam caso o produto fosse vendido na forma em que se apresenta quando de sua separação dos 
demais co-produtos. No segundo caso, o método do valor líquido realizável, o valor de mercado a ser considerado é o valor de venda do produto na sua forma final (pronto para a venda), descontando-se deste todos os valores agregados após o ponto de separação. Exemplificando, considere-se que determinado produto tem valor de venda final de $\mathrm{R} \$$ $2,00 / \mathrm{kg}$. Porém, para a elaboração do produto final foram agregados $\mathrm{R} \$ 1,20 / \mathrm{kg}$ de custos não-conjuntos, portanto, diretamente identificados com este produto (custos diretos). O valor líquido realizável seria de $\mathrm{R} \$ 0,80 / \mathrm{kg}$.

Esse procedimento pode ser adotado quando não existir preço de mercado para o produto na forma em que este se encontra no ponto de separação. Um exemplo deste tipo de caso é o das tripas de suínos, que são processadas para serem utilizadas no processo de fabricação de lingüiças.

Hansen e Mowen (2001) destacam que, ao utilizar-se o preço de venda para a distribuição dos custos conjuntos, "mudanças em preços relativos de mercado são refletidas como mudanças no custo dos produtos, embora seja possível não terem ocorrido mudanças em custos totais ou nos métodos de produção" (HANSEN; MOWEN, 2001). Ao mesmo tempo, os autores lembram que "o método poderia enganar a administração se criasse a impressão de que todos os produtos eram igualmente rentáveis porque mostravam a mesma margem por unidade monetária de custos alocados". (HANSEN; MOWEN, 2001) clui-se que a tentativa de alocação dos custos conjuntos aos produtos originados sempre tenderá a conter certo grau de arbitrariedade. Assim, pode-se dizer que:

“[...] é importante compreender quanto o uso dos custos alocados de produtos conjuntos pode ser enganoso. $\mathrm{Na}$ tomada de decisão relativa a artigos produzidos em conjunto, é preciso lembrar que os produtos são necessariamente produzidos em conjunto. O problema básico da gestão de custos é estabelecer quando e quanto custo é relevante para uma decisão, e não desenvolver uma base para distribuição de custos conjuntos". (HANSEN; MOWEN, 2001)

Algumas áreas que podem ser afetadas por alocação de custos conjuntos são as decisões de produção, o processamento adicional de produtos conjuntos e a determinação de preços de produtos produzidos. Backer e Jacobsen (1978) ressaltam que "conquanto a contabilidade de custos de produtos conjuntos seja essencial para a medição do lucro, os custos de produtos daí derivados têm pouco valor para as decisões a serem tomadas pela direção da empresa" (BACKER; JACOBSEN, 1978).

O Quadro 1 apresenta um resumo dos métodos de alocação dos custos conjuntos apresentados.

Ressalta-se, portanto, que qualquer método de alocação dos custos conjuntos aos diversos produtos originados será sempre agregado de altas doses de subjetividade, podendo tornar-se danoso para a gestão da lucratividade da empresa. Como forma de tratar este problema apresenta-se uma abordagem alternativa baseada na Teoria das Restrições suportada por técnicas de

Portanto, mesmo sendo amplamente utilizado pelas empresas, este método apresenta deficiências, podendo acarretar tomadas de decisão ineficazes.

Método da média ponderada: no intuito de superar a falta de acuracidade do método de unidades físicas, é possível adotar fatores ponderados para alocar os custos aos produtos. Esses fatores ponderados podem incluir em sua formação: a quantidade de material usado, a classificação obtida (extra, especial, padrão), dificuldade de vendas, etc.

As alocações dos custos conjuntos, neste método, levam em conta o fator de ponderação de acordo com a classificação. As imprecisões oriundas deste método são conseqüência da utilização de ponderações que não são apropriadas, ou que se tornam não apropriadas com o passar do tempo. Se taxas arbitrárias forem usadas, os custos resultantes dos produtos individuais apresentarão imprecisões em termos dos custos calculados dos produtos.

Analisando-se os métodos anteriormente descritos, con-
Pesquisa Operacional, assuntos estes tratados a seguir.

\section{A Teoria das Restrições e os Custos Conjuntos}

Antunes Jr. (1998) afirma que o princípio do custeio variável é o ponto de sustentação da Teoria das Restrições (TOC). Nesse sentido assinala que:

"[...] a incomensurabilidade entre a TOC e o sistema tradicional de custos parece existir, muito embora possam ser utilizados elementos importantes da contabilidade tradicional de custos, em particular o Princípio do Custeio Variável, para auxiliar na sustentação das teorias embasadas no paradigma da melhoria nos processos." (ANTUNES Jr., 1998)

No desenvolvimento da Teoria das Restrições, Goldratt e Fox (1992) fazem críticas ao uso das informações da contabilidade de custos para a tomada de decisões. De acordo 
com estes autores, o mundo dos custos está calcado em pressupostos que podem distorcer as informações utilizadas no processo de gestão e tomada de decisão da empresa. Entre os exemplos destes pressupostos pode-se citar o custeamento dos produtos com base no rateio dos custos fixos e a apuração da lucratividade de cada produto apurada com base nestes custos, ou seja, pela diferença entre as receitas de vendas e os custos atribuídos a cada produto pelos critérios estabelecidos. Para Goldratt (1991), o abandono do conceito de "custo individual dos produtos" torna-se a única forma de gerenciar os lucros individuais e, conseqüentemente, a verdadeira contribuição de cada produto para a composição da lucratividade global da empresa.

De acordo com a TOC, os diferentes produtos não possuem custos individuais, mas sim ganhos individuais. $\mathrm{O}$ ganho representa a diferença entre o preço de venda do produto e os gastos diretos e totalmente variáveis relacionados ao mesmo. Para que uma empresa obtenha lucro, o somatório dos ganhos individuais dos produtos multiplicado por suas quantidades vendidas precisa ser maior que os custos fixos e/ou indiretos incorridos na produção destes itens.

Lucro Líquido $=\sum_{i}\left(P V_{i}-C D V_{i}\right) * Q_{i}-C F-C I V$

onde:

$\mathrm{PV}_{\mathrm{i}}=$ preço de venda do produto $\mathrm{i}$

$\mathrm{CDV}_{\mathrm{i}}=$ custo direto variável do produto $\mathrm{i}$

$\mathrm{Q}_{\mathrm{i}}=$ quantidade vendida do produto $\mathrm{i}$

$\mathrm{CF}=$ custos fixos, diretos ou indiretos

$\mathrm{CIV}=$ custos indiretos variáveis

Avaliando-se os possíveis custos conjuntos, a partir da equação (1) construída com base nos conceitos da Teoria das Restrições, pode-se enquadrá-los em dois grupos de custos: i) Fixos (por exemplo: custos de depreciação dos equipamentos, custos de mão-de-obra e custos da estrutura de gestão nas partes do sistema produtivo onde se tem produção conjunta); ii) Custos Indiretos Variáveis, que representam os custos relacionados com a matéria-prima.

Visando operacionalizar os conceitos propugnados pela TOC, é possível utilizar o ferramental disponível na Pesquisa Operacional, principalmente as técnicas de Programação Linear. A idéia a ser perseguida consiste em otimizar uma Função Objetivo relacionada com a maximização do Ganho da Empresa, sujeita a um conjunto de restrições de cunho mercadológico, financeiro e produtivo. Este será objeto de exame no tópico seguinte.

\section{Pesquisa Operacional e Programação Linear}

A Pesquisa Operacional não possui um marco histórico de origem. Possivelmente, os primeiros problemas que foram resolvidos por ela surgiram somente após a Revolução Industrial, na segunda metade do século XVIII. Entretanto, o modelo atual da Pesquisa Operacional surgiu durante a Segunda Guerra, tendo sido desenvolvido para resolver problemas militares de ordem estratégica e tática.

\begin{abstract}
"As raízes da pesquisa operacional começaram a ser traçadas há muitas décadas, quando foram feitas as primeiras tentativas para usar uma abordagem científica na gerência das organizações. Entretanto, o começo da atividade chamada de pesquisa operacional tem sido geralmente atribuído aos serviços militares no início da Segunda Guerra Mundial.” (HILLIER, 1988)
\end{abstract}

A partir do final da Segunda Guerra Mundial, a Pesquisa Operacional se difundiu, passando a ser amplamente utili-

Quadro 1: Resumo dos métodos de distribuição dos custos conjuntos.

\begin{tabular}{|c|c|c|c|}
\hline DESGRIÇÃOO & UNIDADES FÍSICAS & VALOR DE VENDA & MÉDIA PONDERADA \\
\hline BASE RATEIO & Quantidades/Pesos & Preços/Receitas & Índices/Misto \\
\hline PRINĆ́PIO & $\begin{array}{l}\text { Pressupõe que o custo de } \\
\text { aquisição é o mesmo para } \\
\text { todos os produtos. }\end{array}$ & $\begin{array}{l}\text { Quanto maior o preço de venda } \\
\text { maior será o custo absorvido } \\
\text { pelo produto. }\end{array}$ & $\begin{array}{l}\text { Há uma relação entre o volume } \\
\text { de produção, o preço de venda, a } \\
\text { facilidade de venda e a facilidade } \\
\text { de obtenção do produto. }\end{array}$ \\
\hline VANTAGENS & $\begin{array}{l}\text { Qualquer produto } \\
\text { originado de forma } \\
\text { conjunta terá o mesmo } \\
\text { custo unitário. }\end{array}$ & $\begin{array}{l}\text { Evita que determinado } \\
\text { produto apresente margem de } \\
\text { contribuição negativa. }\end{array}$ & $\begin{array}{l}\text { Possibilita que os custos } \\
\text { individuais não sofram oscilação } \\
\text { pelas alterações nos preços de } \\
\text { venda. }\end{array}$ \\
\hline DESVANTAGENS & $\begin{array}{l}\text { Produtos mais nobres } \\
\text { recebem o mesmo custo } \\
\text { de produtos simples e } \\
\text { com pouca aceitação pelo } \\
\text { mercado. }\end{array}$ & $\begin{array}{l}\text { Os custos unitários sofrem as } \\
\text { mesmas variações do preço } \\
\text { de venda. Não demonstra } \\
\text { os ganhos reais obtidos por } \\
\text { determinados produtos. }\end{array}$ & $\begin{array}{l}\text { É extremamente subjetivo, } \\
\text { permitindo que determinados } \\
\text { gestores definam qual produto } \\
\text { deverá absorver maior volume de } \\
\text { custos. }\end{array}$ \\
\hline
\end{tabular}


zada pelas empresas privadas para auxiliar na tomada de decisões.

A Programação Linear é uma das áreas da Pesquisa Operacional que buscam a otimização de um determinado problema que possui muitas soluções possíveis, através da maximização ou minimização de uma função linear. Segundo Iudícibus (1998), a Programação Linear "é um instrumento poderoso de análise e seleção de alternativas ótimas".

Em um processo de resolução de problemas através da Programação Linear, torna-se necessária a elaboração de um modelo matemático que apresente adequadamente o problema a ser resolvido. Para tanto, a correta definição do problema é possivelmente a etapa mais importante para sua resolução.

Segundo Caixeta Filho (2001), a formulação do problema a ser resolvido por programação linear segue alguns passos básicos:

a) definição do objetivo básico do problema - que a princípio deve ser único - com respeito à otimização a ser perseguida. Tal objetivo será assim representado por uma função objetivo, a ser maximizada ou minimizada;

b) para que essa função objetivo possa ser matematicamente especificada, as alternativas possíveis para a ocorrência de tal otimização - as chamadas variáveis de decisão envolvidas - deverão ser definidas. Normalmente assume-se que todas essas variáveis possam assumir somente valores positivos;

c) tais variáveis podem estar sujeitas a uma série de restrições - também conhecidas como restrições do problema - normalmente representadas por inequações.

Ao se definir o modelo de resolução do problema através da Programação Linear, deve-se ter em mente a linearidade das relações entre as variáveis existentes no problema.

Colaborando para a compreensão do processo de modelagem da Programação Linear, Garcia, Guerreiro e Corrar (1997), apresentam o seguinte exemplo para a formulação do modelo matemático de um problema de otimização:

Max. ou Min.

$\mathrm{Z}=\mathrm{c}_{1} \mathrm{x}_{1}+\mathrm{c}_{2} \mathrm{x}_{2}+\ldots \ldots+\mathrm{c}_{\mathrm{n}} \mathrm{x}_{\mathrm{n}}$

Sujeito a:

$$
\begin{aligned}
& \mathrm{a}_{11} \mathrm{x}_{1}+\mathrm{a}_{12} \mathrm{x}_{2}+\ldots \ldots \ldots+\mathrm{a}_{1 \mathrm{n}} \mathrm{x}_{\mathrm{n}} \leq \mathrm{b}_{1} \\
& \mathrm{a}_{21} \mathrm{x}_{1}+\mathrm{a}_{22} \mathrm{x}_{2}+\ldots \ldots \ldots+\mathrm{a}_{2 \mathrm{n}} \mathrm{x}_{\mathrm{n}} \leq \mathrm{b}_{2} \\
& \ldots \ldots \ldots \ldots \ldots \ldots \ldots \ldots \ldots \ldots \ldots \ldots . \\
& \mathrm{a}_{\mathrm{m} 1} \mathrm{x}_{1}+\mathrm{a}_{\mathrm{m} 2} \mathrm{x}_{2}+\ldots \ldots \ldots+\mathrm{a}_{\mathrm{mn}} \mathrm{x}_{\mathrm{n}} \leq \mathrm{b}_{\mathrm{m}}
\end{aligned}
$$

Onde: $x_{i} \geq 0$ e $b_{j} \geq 0$, para $i=1,2, \ldots . n$ e $j=1,2, \ldots . m$ (2)é a função matemática que codifica o objetivo do problema e é denominada função-objetivo.
(3) são as equações matemáticas que codificam as principais restrições identificadas.

A linguagem simbólica é traduzida a seguir:

Z: função a ser maximizada ou minimizada (geralmente ganho ou custo), respeitando o conjunto de elementos do problema ou restrições;

xi:variáveis decisórias que representam as quantidades ou recursos que se quer determinar para otimizar o resultado global;

ci: coeficientes de ganho ou custo por unidade que cada variável é capaz de gerar;

bj:quantidade disponível de cada recurso;

aij: quantidade de recurso que cada variável decisória i consome no recurso $\mathrm{j}$.

A definição das variáveis compreendidas em um modelo de otimização da produção em indústrias frigoríficas de aves será apresentada em uma seção referente ao estudo de caso elaborado em uma indústria instalada na cidade de Capanema (PR).

\section{MÉTODO}

O presente artigo utilizará um caso para analisar a produção conjunta em uma unidade de abate e industrialização de frango. Para isto, será utilizado o método do Estudo de Caso. Utilizando como referência geral o método do Estudo de Caso, será explicitado o Método de Trabalho, ou seja, os passos seguidos para a elaboração da pesquisa.

\section{O Método do Estudo de Caso}

Yin (2001) postula que o estudo de caso é a:

“[...] estratégia escolhida ao se examinarem acontecimentos contemporâneos, mas quando não se pode manipular comportamentos relevantes. O estudo de caso conta com muitas das técnicas utilizadas pelas pesquisas históricas, mas acrescenta duas fontes de evidências que usualmente não são incluídas no repertório de um historiador: observação direta e série sistemática de entrevistas.” (YIN, 2001)

Para a realização desta pesquisa, optou-se por analisar uma empresa frigorífica estabelecida, optando-se pela unidade industrial de Capanema (PR), da empresa Diplomata Agroindustrial e Comercial Ltda. O estudo foi realizado com o intuito de mostrar suas particularidades de produção e identificar suas principais restrições físicas e políticas. Neste sentido, foram utilizadas observações diretas e entrevistas informais com os principais gestores das diversas áreas da empresa. De posse das informações coletadas, foi proposto um modelo de gestão que possibilite à empresa administrar 
seus recursos escassos, de forma a otimizar os resultados obtidos.

$\mathrm{Na}$ análise das informações e na criação do modelo de gestão dos pontos críticos, foi utilizada a Pesquisa Operacional, através da Programação Linear, com o objetivo de aumentar a eficiência na identificação do mix otimizado, ou seja, a combinação de produtos que maximiza o Lucro Líquido da empresa, contemplando o conjunto de restrições físicas de produção.

\section{Método de trabalho}

A elaboração deste estudo de caso foi realizada através dos passos apresentados a seguir:

\section{Passo 1 - Estruturação do Estudo de Caso}

Para a estruturação do estudo de caso foram adotadas as seguintes etapas de trabalho.

- Visita e análise da empresa em estudo

Foram feitas 11 visitas à unidade industrial de Capanema (PR) da empresa Diplomata Agroindustrial Ltda., no intuito de conhecer os processos produtivos e analisar in loco as restrições existentes no parque industrial. Durante essas visitas, foram coletados os dados necessários para o desenvolvimento do modelo de otimização ora apresentado.

- Entrevistas informais com os gestores da empresa

Com o objetivo de compreender as dificuldades enfrentadas, as visões sobre a otimização de resultados e as restrições e gargalos da empresa, foram realizadas visitas e entrevistas no escritório administrativo da empresa, localizado em Cascavel (PR). Foram realizadas conversas informais com os gerentes e supervisores que participam do processo de gerenciamento das atividades relacionadas ao abate, industrialização e vendas de frangos e produtos derivados. Entrevistas informais mais longas e detalhadas foram realizadas com os profissionais que atuam na: gerência industrial, gerência administrativa, gerência de vendas e com o diretor presidente.

- Coleta de dados e informações

Para a coleta de dados e informações adotou-se a lógica proposta pela Teoria das Restrições, ou seja, com foco nos dados e informações relevantes para a montagem do modelo. A coleta de dados e informações foi elaborada através: i) de conversas informais com as gerências da empresa; ii) de observações visuais na própria empresa; iii) análise de documentos solicitados e/ou apresentados pela empresa.

\section{Passo 2 - Elaboração de modelo de otimização de mix de produção}

O modelo de otimização do mix de produção foi elabo- rado seguindo as técnicas da Programação Linear. Para isso foi utilizado o software Lindo para a resolução do problema. Todos os dados utilizados para o processo de modelagem foram obtidos durante as visitas efetuadas à empresa ou através de relatórios de gestão já elaborados para fins de decisão pela área de controladoria da mesma (Passo 1).

\section{Passo 3 - Elaboração de comparativo entre o modelo de decisão atualmente existente na empresa e o modelo proposto}

Através do modelo de otimização proposto foram comparados: i) a produção real da empresa; ii) adoção do mix otimizado. As simulações dos modelos propostos levaram em torno de 5 minutos para serem rodadas, tendo sido utilizado um computador Athlon XP 2.6 com 512 MB de RAM. A partir desta comparação foram desenvolvidas as conclusões da presente pesquisa.

\section{O PROCESSO DE OTIMIZAC̣ÃO DA PRODUC̣ÃO EM INDÚSTRIAS DE PRODUÇÃO CONJUNTA ATRAVÉS DA PROGRAMAC̣ÃO LINEAR}

O processo de otimização da produção foi elaborado através do estudo de caso descrito a seguir.

\section{Aspectos Conceituais Gerais}

Para otimizar um determinado processo produtivo objetivando maximizar os resultados torna-se necessário determinar a lucratividade dos produtos que estão sendo vendidos.

Em termos de produção conjunta, é difícil conhecer o valor efetivo que cada produto gera para os resultados da empresa. Nesse tipo de sistema produtivo é relevante propor um modelo de gestão diferenciado para tratar o tema, uma vez que decisões baseadas na lucratividade individual dos produtos apresentam subjetividades consideráveis.

Uma vez identificados os problemas associados à Produção Conjunta, a idéia básica consiste em propor métodos que permitam melhorar as tomadas de decisão envolvendo a lucratividade da empresa. Uma análise detalhada dos custos produtivos deste tipo de indústria aponta para a necessidade de gerar um modelo que considere de forma diferenciada os custos da matéria-prima frango vivo na apuração da lucratividade que cada produto gera para a empresa. Na seqüência, desenvolve-se o raciocínio adotado para tratar o tema da "produção conjunta" de forma alternativa.

\section{O Modelo Proposto}

A lucratividade desses produtos é composta pelo seu preço de venda descontando-se todos os gastos variáveis e diretos de produção e vendas. Ou seja, o preço bruto menos as despesas com impostos, com frete de entrega, com 
comissões sobre vendas, os custos de embalagens além de outros gastos variáveis agregados aos produtos após o ponto de separação.

O custo do frango vivo, principal matéria-prima do produto final, não necessita ser considerado na apuração do lucro dos produtos vendidos. Tais custos, apesar de variáveis, precisam de rateios para serem alocados aos produtos. Isto porque estes custos são indiretos em relação aos produtos finais deste tipo de indústria.

buição do produto. Isto porque nem todos os custos variáveis foram considerados em seu cálculo.

Para a elaboração do modelo de otimização através da Programação Linear torna-se necessário identificar as restrições existentes no processo produtivo em análise. Como a empresa trabalha somente com as linhas de abate de frango e corte das aves, não existe processo de transformação dos produtos primários derivados destas linhas.

A Figura 2 apresenta o fluxo de produção da indústria visando definir as restrições existentes no sistema produtivo. Esta explicita que o processo de industrialização do frango caracteriza-se como produção contínua, trabalhando com linha de produção seqüencial até a entrada do frango no processo de resfriamento (Chiller de resfriamento). Neste ponto surge a primeira decisão do gestor: embalar frango inteiro ou encaminhar os

A lucratividade individual dos produtos elaborados pela empresa foi definida, utilizando como exemplo três produtos, conforme explicitado na Tabela 1.

Os cálculos dos Ganhos Unitários dos produtos $(\mathrm{R} \$ / \mathrm{kg})$ foram feitos para todos os produtos elaborados pela empresa. Neste estágio do processo de cálculo é preciso considerar que ainda não foram descontados os gastos com estrutura da empresa e os gastos com a matéria-prima de produção conjunta - o custo do frango vivo abatido.

Visando a elaboração da análise proposta foram usados os valores médios praticados em um mês de operação da empresa. Esse procedimento possibilitou a realização de uma análise comparativa entre o Ganho obtido pela empresa neste mês e sua capacidade de Ganho com a utilização da otimização da produção através da Programação Linear.

É relevante considerar que o valor do "Ganho Unitário" calculado não deve ser analisado como margem de contri- mesmos frangos para a produção de cortes? No setor de cortes, novas decisões deverão ser tomadas. Por exemplo: i) qual o nível de processamento que se dará a determinado volume de matéria-prima?; ii) produzir peito com osso ou desossá-lo até obter o filé de peito?

Em função das características do sistema produtivo da empresa, não são observadas grandes variações nos níveis de produção ou nas características dos produtos gerados. As variações dependem quase que exclusivamente da disponibilidade de matéria-prima e das ordens de produção.

Uma vez desenhado e compreendido em profundidade o sistema produtivo da empresa, foi realizada a modelagem, sendo descritas as restrições do sistema produtivo. Para a análise do modelo de otimização foi utilizado um Solver de Programação Linear denominado Lindo, de amplo uso empresarial.

O processo de modelagem, de acordo com a sintaxe do

Tabela 1: Exemplo demonstrativo do Ganho Unitário dos produtos.

\begin{tabular}{|c|c|c|c|}
\hline DESCRIÇÃO/PRODUTO & $\begin{array}{l}\text { FRANGO INTEIRO } \\
\text { TEMPERADO }\end{array}$ & $\begin{array}{l}\text { PEITO COM OSSO } \\
\text { COM PELE }\end{array}$ & $\begin{array}{c}\text { COXA COM SOBRECOXA } \\
\text { DESOSSADA }\end{array}$ \\
\hline Preço Bruto $(\mathrm{R} \$ / \mathrm{kg})$ & 2,5100 & 3,3900 & 4,5330 \\
\hline (-) Impostos sobre Vendas $(\mathrm{R} \$ / \mathrm{kg})$ & 0,2924 & 0,3949 & 0,5281 \\
\hline (-) Comissões (R\$/kg) & 0,0470 & 0,0509 & 0,0680 \\
\hline (-) Fretes $(\mathrm{R} \$ / \mathrm{kg})$ & 0,1613 & 0,1613 & 0,1613 \\
\hline (-) Embalagens $(R \$ / \mathrm{kg})$ & 0,0835 & 0,0767 & 0,1233 \\
\hline (-) Outras Matérias-Primas $(\mathrm{R} \$ / \mathrm{kg}$ ) & 0,0189 & 0,0000 & 0,0000 \\
\hline (=) Ganho Unitário $(R \$ / \mathrm{kg}$ ) & 1,9132 & 2,7062 & 3,6523 \\
\hline
\end{tabular}


solver, parte da definição da função objetivo, compreendida pela definição da fórmula de maximização ou minimização do problema que se quer resolver. A seguir são consideradas as restrições do problema. Na seqüência explicita-se o procedimento prático utilizado:

\section{Função Objetivo}

Para o desenvolvimento do modelo apresentou-se a Função Objetivo para a maximização do lucro da empresa. Neste caso, entende-se por 'maximização do lucro' a maximização do valor total obtido através da multiplicação entre o Ganho Unitário por produto e o volume vendido de cada produto.

$$
\begin{aligned}
\operatorname{Max} Z= & \sum_{i} \sum_{m}\left(G_{i} * V_{i, m}\right) \\
& \text { para } \mathrm{i}=1, \ldots, \text { número de produtos finais } \\
& \text { para } \mathrm{m}=1, \ldots, \text { número de meses }
\end{aligned}
$$

Onde:

$\mathrm{G}_{\mathrm{i}}$ : Ganho Unitário do produto final "i"

$\mathrm{V}_{\mathrm{i}, \mathrm{m}}$ : volume (em mil $\mathrm{kg}$ ) a ser vendido do produto final "i", no período "m"

\section{Restrições}

As principais restrições do modelo de otimização proposto foram:

Restrições de mercado - representadas pelos volumes mínimos e máximos de vendas para cada produto. Esses volumes foram definidos de acordo com as estimativas da área de vendas da empresa, visando relacionar a produção com a capacidade de absorção dos produtos pelo mercado. $\mathrm{O}$ equacionamento dessas restrições está apresentado a seguir:

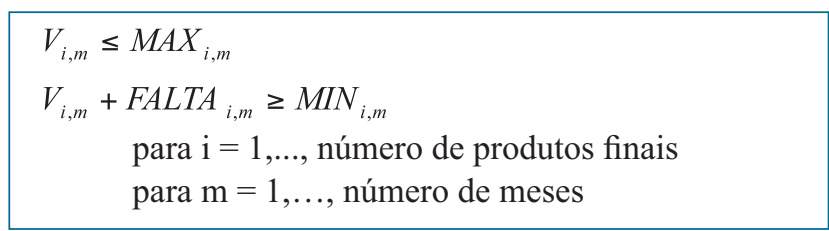

Onde:

$\mathrm{V}_{\mathrm{i}, \mathrm{m}}$ : volume (em mil $\mathrm{kg}$ ) a ser vendido do produto final "i" no período " $\mathrm{m}$ "

$\mathrm{MAX}_{\mathrm{i}, \mathrm{m}}$ : quantidade máxima de mercado do produto final "i" no período " $\mathrm{m}$ "

$\mathrm{MIN}_{\mathrm{i}, \mathrm{m}}$ : quantidade mínima de mercado do produto final "i" no período "m"

Figura 2: Processo de abate e industrialização de frangos.

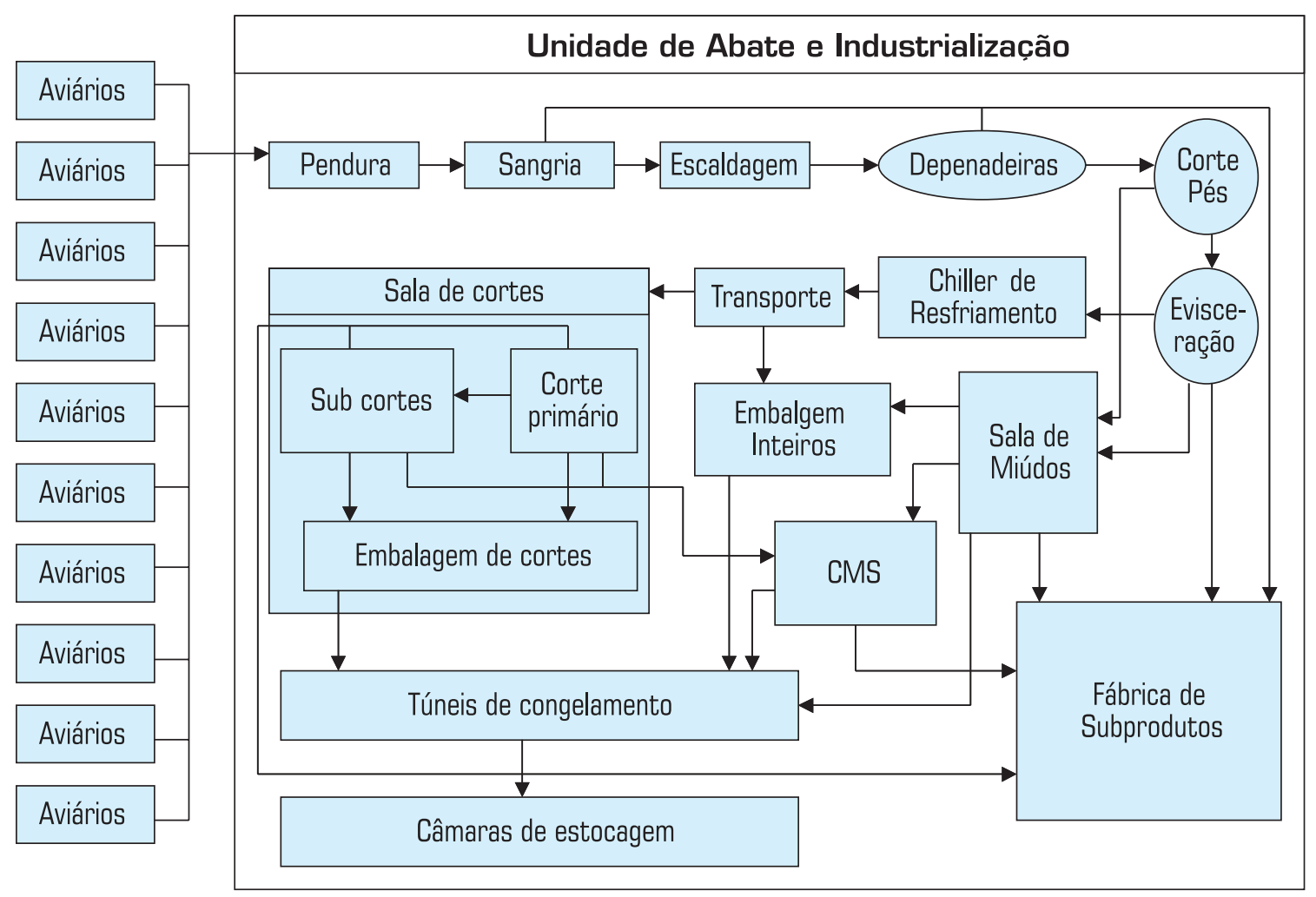


FALTA $_{\mathrm{i}, \mathrm{m}}$ : quantidade mínima de mercado não atendida do produto final "i" no período " $\mathrm{m}$ "

Restrições de abate - a capacidade total de produção é limitada pela disponibilidade de aves para o abate, desta forma limitando a quantidade total de produtos finais a ser produzida. O equacionamento dessa restrição está apresentado abaixo:

$$
\begin{gathered}
\sum_{i}\left(P_{i, m}\right) \leq F O R_{m} \\
\text { para } \mathrm{i}=1, \ldots, \text { número de itens básicos } \\
\text { para } \mathrm{m}=1, \ldots, \text { número de meses }
\end{gathered}
$$

Onde:

$\mathrm{P}_{\mathrm{i}, \mathrm{m}}$ : quantidade produzida (em mil $\mathrm{kg}$ ) do produto final "i" no período " $\mathrm{m}$ "

FOR ${ }_{\mathrm{m}}$ : quantidade de aves abatidas (em mil kg) no período "m"

Restrições de matéria-prima - representadas pelo volume máximo de matéria-prima frango abatido para a produção dos diversos produtos a serem produzidos. São consideradas, também, as restrições de disponibilidade das matérias primas descendentes. Por exemplo, o volume total de peito que poderá ser desossado está restrito pelo volume de peito com osso gerado a partir do abate do frango. $\mathrm{O}$ equacionamento dessa restrição está apresentado abaixo:

$$
\begin{aligned}
& Q T_{p, m}-\sum_{i} M P_{i, p, m}=0 \\
& \text { para } \mathrm{p}=1, \ldots, \text { número de matérias-primas } \\
& \text { para } \mathrm{m}=1, \ldots, \text { número de meses }
\end{aligned}
$$

Onde:

$\mathrm{MP}_{\mathrm{i}, \mathrm{p}, \mathrm{m}}$ : quantidade da matéria-prima "p" utilizada no mês "m" para produzir "i"

$\mathrm{QT}_{\mathrm{p}, \mathrm{m}}$ : quantidade total da matéria-prima "p" necessária no mês "m"

Restrições de congelamento - referem-se ao tempo disponível de congelamento dos produtos acabados e a capacidade de congelamento por hora. Este conjunto de restrições (restrições volumétricas de congelamento) é um dos fatores que impede o aumento no volume de produção total de determinados produtos da empresa. $\mathrm{O}$ equacionamento dessa restrição está apresentado a seguir:

$$
\begin{gathered}
\sum_{i}\left(T_{i, j} * P_{i, m}\right) \leq C_{j, m} * Q T_{j} \\
\text { para } \mathrm{j}=1, \ldots, \text { número de recursos } \\
\text { para } \mathrm{m}=1, \ldots, \text { número de meses }
\end{gathered}
$$

Onde:

$\mathrm{T}_{\mathrm{i}, \mathrm{j}}$ : tempo de atravessamento do produto " $\mathrm{i}$ " no recurso " $\mathrm{j}$ ” $\mathrm{P}_{\mathrm{i}, \mathrm{m}}$ : quantidade produzida do produto "i" no mês "m"
$\mathrm{QT}_{\mathrm{j}}$ : quantidade total de material que pode estar no recurso "j" no mesmo instante

$\mathrm{C}_{\mathrm{j}, \mathrm{m}}$ : número de horas normais disponíveis no recurso “ $\mathrm{j}$ ” no mês "m"

Restrições do setor de cortes - a sala de cortes de frango é limitada, não permitindo o corte de todos os frangos abatidos. Portanto, existe necessariamente a existência de certo volume de produção de frango inteiro. $\mathrm{O}$ equacionamento dessa restrição está apresentado abaixo:

$$
\begin{gathered}
-R H X_{j, m}+\sum_{i}\left(T_{i, j} * P_{i, m}\right) \leq C_{j, m} \\
\text { para } \mathrm{j}=1, \ldots, \text { número de recursos } \\
\text { para } \mathrm{m}=1, \ldots, \text { número de meses }
\end{gathered}
$$

Onde:

$\mathrm{T}_{\mathrm{i}, \mathrm{j}}$ : tempo de atravessamento do produto " $\mathrm{i}$ " no recurso " $\mathrm{j}$ "

$\mathrm{C}_{\mathrm{j}, \mathrm{m}}^{\mathrm{m}}$ : número de horas normais disponíveis no recurso “ $\mathrm{j}$ ” no mês "m"

$\mathrm{P}_{\mathrm{i}, \mathrm{m}}$ : quantidade do produto "i" produzida no mês "m"

$\mathrm{RHX}_{\mathrm{j}, \mathrm{m}}$ : quantidade de horas extras disponíveis no recurso "j" no mês "m"

Restrições do setor de temperados - o número de máquinas existentes para a injeção de temperos no frango inteiro ou nos cortes de frango não é suficiente para temperar toda a produção. A modelagem destas restrições é semelhante à das restrições do setor de cortes apresentada anteriormente.

Para auxiliar na modelagem das restrições, principalmente as relativas à matéria-prima, elaborou-se a árvore de cortes da indústria. Essa árvore consiste na identificação dos rendimentos de abate e cortes que se obtêm em cada processo produtivo. Apresenta-se, a título de exemplificação, os rendimentos de três processos produtivos:

1) Rendimentos originados do abate de frango para produção de frango inteiro com miúdos:

\begin{tabular}{|l|r|}
\hline Frango inteiro com miúdos & $87,95 \%$ \\
\hline Coração de frango & $0,51 \%$ \\
\hline Farinha de penas para ração & $3,77 \%$ \\
\hline Farinha de vísceras para ração & $2,43 \%$ \\
\hline Graxa industrial para ração & $1,93 \%$ \\
\hline
\end{tabular}

2) Rendimentos originados do corte da carcaça de frango:

\begin{tabular}{|l|l|}
\hline Peito com osso com pele & $32,70 \%$ \\
\hline Perna com osso com pele & $34,21 \%$ \\
\hline Asa inteira & $11,11 \%$ \\
\hline Dorso com sambiquira & $20,04 \%$ \\
\hline
\end{tabular}


3) Rendimentos originados da desossa do peito com osso com pele:

\begin{tabular}{|l|r|}
\hline Peito sem osso sem pele & $49,22 \%$ \\
\hline Cartilagem de peito & $1,03 \%$ \\
\hline Retalhos & $6,86 \%$ \\
\hline Filezinho de peito & $13,92 \%$ \\
\hline Carne mecanicamente separada & $18,24 \%$ \\
\hline Pele & $9,78 \%$ \\
\hline
\end{tabular}

Os rendimentos explicitados foram produzidos a partir de testes efetuados dentro da indústria, procurando reproduzir, com fidedignidade, os processos normais de produção. Destaca-se que esses rendimentos não sofrem grandes alterações, ou seja, ao cortar $100 \mathrm{~kg}$ de carcaça de frango - item 2 - obter-se-ão em média $32,7 \mathrm{~kg}$ de peito com osso, 34,21 $\mathrm{kg}$ de perna com osso com pele, $11,11 \mathrm{~kg}$ de asa inteira e $20,04 \mathrm{~kg}$ de dorso de frango.

A árvore de cortes elaborada para a realização do trabalho contemplou todos os produtos da empresa. dual na maximização da lucratividade. Utilizaram-se para o cálculo da margem de contribuição os valores unitários gerados pela empresa através da distribuição dos custos de matéria-prima através do rateio proposto pelo método das ponderações.

Essa última simulação foi feita com o objetivo de mostrar que, mesmo utilizando-se dos princípios de otimização através da Programação Linear, se a base conceitual de lucro não estiver correta, o valor do ganho global da empresa não será o ótimo.

A Tabela 3 apresenta o comparativo dos ganhos/lucros obtidos em cada uma das três situações analisadas. Observa-se que existem também diferenças nos volumes de produção. A análise demonstrou que tais diferenças relacionam-se com os distintos rendimentos derivados da alteração no mix de produção. Ao alterar-se o mix de produção, pode-se gerar um menor volume total, devido às quebras de matérias-primas descartadas. Ao desossar a perna do frango, por exemplo, haverá o descarte de volume significativo de ossos que reduzem o volume total de produtos disponibilizados para venda.

\section{Resultados obtidos}

Na Tabela 2 são apresentados os dados reais da empresa utilizados para a elaboração do modelo de otimização. O objetivo consiste em comparar o resultado real da produção da empresa com sua capacidade de lucratividade utilizando o modelo proposto.

Utilizando-se do modelo proposto foi determinado o mix de produção que levaria à lucratividade máxima da empresa. Os volumes de produção sugeridos pelo solver foram valorados conforme os Ganhos Unitários dos produtos, visando apurar o resultado que a empresa obteria se fossem produzidos tais volumes.

Também foram valorizados os volumes reais de produção que a empresa obteve com o abate no mês em análise pelos ganhos unitários de cada produto. Ainda, foi feita uma simulação da otimização da produção utilizando-se a margem de contribuição dos produtos como ganho indivi-

\section{e acordo com a TOC, os diferentes produtos não possuem custos individuais, mas sim ganhos individuais.}

Os custos de matéria-prima e de estrutura são os mesmos para as três análises em função da utilização do mesmo volume de abate em todas as simulações.

A Tabela 3 mostra significativas diferenças nas simulações. A diferença entre a rentabilidade atual da empresa e sua capacidade otimizada é de R $\$ 133.584,00$, ou $15,84 \%$, no mês em análise. Essa diferença, se considerada no período de um ano, representaria um valor de $\mathrm{R} \$ 1.603 .008,00$ de incremento na lucratividade total da empresa.

Tabela 2: Disponibilidade de matéria-prima e restrições de cortes da indústria.

\begin{tabular}{|l|c|c|}
\hline \multicolumn{1}{|c|}{ DESGRIÇÃO } & VALOR & UNIDADE \\
\hline Abate mensal & 2.848 .523 & Cabeças \\
\hline Peso médio por cabeça & 2.377 & $\mathrm{Kg}$ \\
\hline Peso total do abate & 6.769 .720 & $\mathrm{Kg}$ \\
\hline Custo total do abate & $10.299 .452,00$ & Cabeças \\
\hline Capacidade sala de cortes & 2.278 .815 & $\mathrm{Kg}$ \\
\hline Peso total sala cortes & 5.416 .751 & \\
\hline
\end{tabular}


Tabela 3: Comparativo entre os resultados obtidos.

\begin{tabular}{|c|c|c|c|}
\hline DESCRIÇÃO & MIX ATUAL & $\begin{array}{c}\text { OTIMIZAÇÃO } \\
\text { MARGEM UNITÁRIA }\end{array}$ & $\begin{array}{c}\text { OTIMIZAÇÃO } \\
\text { GANHO UNTÁRIO }\end{array}$ \\
\hline Volumes totais de produção & 5.959 .772 & 5.938 .109 & 6.030 .959 \\
\hline Ganho total antes MP e estrutura & 12.194.985 & 12.260.024 & 12.328.569 \\
\hline Custo matéria-prima & 10.299.452 & 10.299.452 & 10.299.452 \\
\hline Custo da estrutura (fixos) & 1.052 .447 & 1.052 .447 & 1.052 .447 \\
\hline Resultado das vendas $(R \$)$ & 843.086 & 908.125 & 976.670 \\
\hline Diferença resultado com mix atual $(R \$)$ & & & 133.584 \\
\hline Diferença resultado com mix atual [\%] & & & $15,84 \%$ \\
\hline Diferença result. com otimiz. Margem $[R \$$ ] & & & 68.545 \\
\hline Diferença result. com otimiz. Margem [\%] & & & $7,55 \%$ \\
\hline
\end{tabular}

A análise comparativa entre a otimização do ganho unitário proposto e a otimização da margem de contribuição revela uma diferença de $\mathrm{R} \$ 68.545,00$ ou $7,55 \%$ no mês em análise. Considerada em um período de um ano, essa diferença poderia significar um valor de $\mathrm{R} \$$ $822.540,00$ no lucro total da empresa. Através desta análise fica claro que a utilização de rateios para obtenção de valores que auxiliarão na tomada de decisões pode afetar significativamente os resultados econômico-financeiros da organização.

\section{CONCLUSÕES}

Os processos decisórios em empresas de produção conjunta são complexos. A idéia de distribuir os custos conjuntos de acordo com as bases de rateio propostas pelos métodos tradicionais (por exemplo, visando apurar a lucratividade dos produtos) tende a não qualificar de forma suficiente os processos de decisão envolvidos na questão.

O estudo desenvolvido é esclarecedor neste sentido, na medida em que explicita que a maximização da lucratividade da empresa pode ser feita sem a necessidade da adoção de métodos de rateio para os custos conjuntos. $\mathrm{O}$ estudo mostrou que uma forma mais eficaz de analisar o problema pode ser obtida através da adoção da noção conceitual de 'Ganho Unitário'. Isto porque quanto maior a ganho total da empresa, gerado pela venda dos produtos, maior será o lucro total obtido.

Porém, a adoção do conceito de Ganho Unitário deve ser percebida no âmbito mais amplo da Teoria das Restrições. O modelo proposto, partindo dos conceitos propugnados na Teoria das Restrições, utiliza a Programação Linear no intuito de planejar o mix de produção que leve à maximização da lucratividade da empresa.
Artigo recebido em 15/06/2005
Aprovado para publicação em 23/03/2006 
- Referências Bibliográficas

ANTUNES JR., J. A. V. Em direção a uma teoria geral do processo na administração da produção: Uma discussão a partir da possibilidade de unificação da teoria das restrições e da teoria que sustenta a construção dos sistemas de produção com estoque zero. Tese de doutorado em administração, Porto Alegre: Programa de Pós-Graduação em Administração, Universidade Federal do Rio Grande do Sul, 1998

BAKER, M.; JACOBSEN, L. E. Contabilidade de Custos. São Paulo: McGraw-Hil do Brasil, 1978.

CAIXETA-FILHO, José Vicente. Pesquisa Operacional. São Paulo: Atlas, 2001.

GARCIA, S. GUERREIRO, R., CORRAR, L. J. Teoria das Restrições e Programação Linear.
Trabalho apresentado no V Congresso Internacional de Custos, Acapulco, México, 1997.

GOLDBARG, M. C.; LUNA, H. P. L. Otimização Combinatória e Programação Linear: modelos e algoritmos. São Paulo: Campus, 2000.

GOLDRATT, E. M. A síndrome do palheiro: garimpando informação num oceano de dados. São Paulo: Educator, 1991, $2^{\text {a }}$ ed.

GOLDRATT, E. M; FOX, R. E. A corrida pela vantagem competitiva. São Paulo: Educator, 1992.

HANSEN, D. R.; MOWEN, M., Gestão de Custos Contabilidade e Controle: 3 ed. São Paulo: Pioneira, 2001.
HILLIER, F. S. Introdução a pesquisa operacional. Rio de Janeiro: Campus, 1998.

HORNGREN, C. T. Contabilidade de Custos: um enfoque administrativo. São Paulo: Atlas, 1986.

IUDICIBUS, S. de. Contabilidade Gerencial: 6a ed. São Paulo: Atlas, 1998.

LINDO. Disponível em: <http://www. lindo.com $>$, acessado em 21 de agosto de 2003.

MARSHALL, P. D.; DOMBROWSKI, R. F. A small business review of accounting for primary products, byproducts and scrap. The National Public Accountant, ABI/INFORM Global, p. 10, Fev/Mar 2003
MARTINS, E. Contabilidade Custos. $9^{\mathrm{a}}$ ed São Paulo: Atlas, 2003.

NOREEN, E.; SMITH, D.; MACKEY, J. A Teoria das Restrições e suas Implicações na contabilidade Gerencial. São Paulo: Educator, 1996.

PEREIRA, C. A. Ambiente, empresa, Gestão e Eficácia. In: CATELLI, Armando (coord.), Controladoria: uma abordagem da gestão econômica - GECON. São Paulo: Atlas, 1999. (Capítulo 1 p.35-78).

VICECONTI, P. E. V; NEVES, S. das. Contabilidade de custos: um enfoque direto e objetivo. São Paulo: Frase Editora, 2000.

YIN, R. K. Estudo de Caso. 2 ed. Porto Alegre: Bookmann, 2001.

\section{- Sobre os autores}

\section{Ricardo Augusto Cassel}

Universidade do Vale do Rio dos Sinos - UNISINOS

Prof. do Programa de Pós-Graduação em Engenharia de Produção e Sistemas

End.: Av. Unisinos, 950 - São Leopoldo, RS - Brasil - CEP: 93022-000

Tel: (51) 81246238

Fax: (51) 35908172

Email: cassel@unisinos.br

\section{José Antônio Valle Antunes Jr.}

Universidade do Vale do Rio dos Sinos - UNISINOS

Prof. do Programa de Pós-Graduação em Engenharia de Produção e Sistemas

End.: Av. Unisinos, 950 - São Leopoldo, RS - Brasil - CEP: 93022-000

Tel: (51) 81248318

Fax: (51) 35908172

Email: junico@produttare.com.br

\section{Vilmar Oenning}

Universidade Comunitária Regional de Chapecó - Unochapecó

Departamento de Ciências Sociais Aplicadas

End.: Rua Senador Atílio Fontana, 591e - Chapecó, SC - Brasil - CEP: 89809-000

Tel: (49) 99148035

Email: oenning@unochapeco.edu.br 